\title{
非線形離散值系の最短時間問題の数值解法†
}

\author{
辻 節 三*・伊 藤 輝 生** \\ * 九州大学工学部 福岡市東区大字箱崎 3576 \\ ** 九州工業大学 北九州市戸烟区仙水町 1-1 \\ (昭和 47 年 1 月 20 日 受付)
}

\section{Numerical Solution of the Minimum-Time Problem of Nonlinear Discrete Systems}

\author{
Setsuzo TsujI* and Teruo IroH** \\ $\left(\begin{array}{rl}* & \text { Faculty of Engineering, Kyushu University, Fukuoka } \\ * * & \text { Kyushu Institute of Technology, Kitakyushu }\end{array}\right)$
}

(Received January 20, 1972)

\begin{abstract}
The problem considered in this paper is the minimum-time problem of nonlinear discrete systems with state and control constrained. In the first half of this paper, the algorithm is given, which solves the minimum-time problem by solving the sequence of the fixed endpoint optimal control problem by the penalty function method. The convergence proof of the algorithm is given. In the latter half of this paper, another algorithm is given, which minimizes the penalty functions which appear in the above fixed endpoint optimal control problems and necessarily contain Heaviside's step functions. This algorithm is especially interesting in the case where the system and the constraints are linear. An illustrative example is given.
\end{abstract}

\section{1. まえがき}

これまで, 線形離散值系の最短時間問題の数值解法 《ついては種々に研究されているが11 5)，系が非線形 であったり状態に不等式制限がある場合には，最短時 間問題の数值解の手法についてあまり研究されていな いようである。 また，他方に祘いて，関数の極值を求 める手法として種々のこう配法が研究されて特り6),7), 罰関数法を用いることにより, 等式括よび不等式制限 条件付極值問題が制限のない極值問題として, 各種こ う配法により解かれることが示されている8 ,9). そこ で本論文は非線形離散值系に和いて, 状態抒よび操作 量に不等式制限がある場合に, 最短時間問題の数值解 を，罰関数法を適用して統一的に求める方法について 述べる.これは, 著者らの文献（5）の結果を上述の 制限付非線形離散值系に拡張したものであり, 初期点 と目標点を両端点としある評価を最小化する固定端点 最適制御問題の解を与えるよらな罚関数を設定し, 種 々の時間を選んで逐次罰関数の極值を求めつつ固定端 点問題の解の存在する最小の時間(すなわち最短時間)

$\dagger$ 第 14 回自動制御連合講演会で発表 (昭 $46 \cdot 11$ )
求をめる方法である. 本論交の前半に括いて，この方 法を実行するアルゴリズムと収束の証明について述べ る. また後半に执いて，上述の罰関数としてへビサイ ドのステップ関数をるつ関数を採用すること，拉よび 最短時間問題のアルゴリズムの実行が罰関数の極值の 計算に本質的に依存することから；とくにへビサイド のステップ関数を含む関数をステップ状の不連続性を 除去して極值を計算するアルゴリズムを提案し収束の 証明を行なった．とくに系拉よび不等式制限が線形で あり評価が 2 次の場合には, この方法はニュートン法 を包含するアルゴリズムになる. 例題の計算結果は, 罰関数法による方法がかなり良い精度の解を与える可 能性があることを示している.

\section{2. 最短時間問題の数值解法}

最短時間問題はつぎのように定式化できる. 非線形 離散值系をあらわす等式制限条件として,

$$
\begin{gathered}
\boldsymbol{x}(k+1)=\boldsymbol{f}(\boldsymbol{x}(k), \boldsymbol{u}(k), k), \boldsymbol{x}(0)=\boldsymbol{x}_{0} \\
\boldsymbol{f}(0,0, k)=0, k=0, \cdots, N-1, \cdots
\end{gathered}
$$

であるとする. ここで, $\boldsymbol{x}(k)$ は $n$ 次元状態べクトル， $\boldsymbol{u}(k)$ は $r$ 次元操作ベクトル, $\boldsymbol{f}(\cdot)$ はベクトル值関数, 
Nは正の整数であるとする.ささらに, 状態拉よび操作 量に対する不等式制限条件が，

$$
\begin{aligned}
& g_{i}(\boldsymbol{x}(1), \cdots, \boldsymbol{x}(N), \boldsymbol{u}(0), \cdots, \boldsymbol{u}(N-1), N) \leqq 0, \\
& \quad i=1, \cdots, p_{N}
\end{aligned}
$$

で与えられるものとする.最短時間問題は，(1)，(2) 式の等式抹よび不等式制限条件のもとで, 最終值 $\boldsymbol{x}$ $(N)=0$ となる最小の時間 $N$ を求める問題となる.

いま, $\boldsymbol{x}(k), \boldsymbol{u}(k-1), k=1, \cdots, N$ ，をまとめたべ クトル $\boldsymbol{z}(N)$ と $\boldsymbol{z}(N)$ を $\boldsymbol{x}(N)$ に変換する行列 $S$ (N) を考光,

$$
\begin{aligned}
& \boldsymbol{z}(N)=\left[\boldsymbol{x}^{\prime}(1) \cdots \boldsymbol{x}^{\prime}(N) \boldsymbol{u}^{\prime}(0) \cdots \boldsymbol{u}^{\prime}(N-1)\right]^{\prime} \\
& S(N) \boldsymbol{z}(N)=\boldsymbol{x}(N)
\end{aligned}
$$

とする.ここで, 右肩'はべクトルまたは行列の転置 をあらわするのとする，そらすれば（1）式は $z(N)$ 北関する $n \times N$ 個の等式制限条件をあらわすことに なるから， $n \times N$ ベクトル值関数 $\boldsymbol{F}(\cdot)$ により,

$$
\boldsymbol{F}(\boldsymbol{z}(N), N)=0
$$

そ書くことができる。同様に（3）式は，

$$
g_{i}(z(N), N) \leqq 0, \quad i=1, \cdots, P_{N}
$$

と書ける。ささらに，ある評価 $J(\boldsymbol{z}(N), N)$ を最小に 乙, 初期点と原点を両端点とする固定端点問題の解を 与えるような罰関数は, 文献 (8) により,

$$
\begin{aligned}
& I(z(N), N, \varepsilon)=\|S(N) z(N)\|^{2}+\|F(z(N), N)\|^{2} \\
& \quad+\sum_{i=1}^{p_{N}} H\left(g_{i}(z(N), N)\right)\left(g_{i}(z(N))\right)^{2} \\
& \quad+\varepsilon J(z(N), N)
\end{aligned}
$$

と書くことができる。ここで，には正の值をとるパラ メータとし, $H(\cdot)$ はへビサイドのステップ関数であ る. (7) 式の第 1 項は, $\boldsymbol{x}(N)(=S(N) \boldsymbol{z}(N))$ を原 点に到達させるための罚であり, 第 2 項は, 系の方程 式の等式制限条件を満足させるための罚であり, 第 3 項は, $g_{i}(z(N), N) \leqq 0$ のときは，零であり， $g_{i}(z$ $(N), N)>0$ のとき正の值となるから,$g_{\imath}(z(N), N)$ $\leqq 0, i=1, \cdots, p_{N}$ を満足させるための罰である. そし て零に収束する数列 $\varepsilon_{i}$ を,

$$
\varepsilon_{1}>\varepsilon_{2}>\cdots>, \lim _{i \rightarrow \infty} \varepsilon_{i}=0
$$

とし，各 $\varepsilon_{i}$ に対して，

$$
\min I\left(z(N), N, \varepsilon_{i}\right)=I\left(z\left(N, \varepsilon_{i}\right), N, \varepsilon_{i}\right)
$$

そすれば， ある適当な仮定のもとに以下の一連の関係 式を得る ${ }^{8)}$. ここで, $\boldsymbol{z}\left(N, \varepsilon_{i}\right)$ は, $I\left(\boldsymbol{z}(N), N, \varepsilon_{i}\right)$ の 最小值を与觉る值である.

$$
\begin{aligned}
& \lim _{i \rightarrow \infty} \frac{1}{\varepsilon_{i}}\left\{\left\|S(N) \boldsymbol{z}\left(N, \varepsilon_{i}\right)\right\|^{2}+\left\|\boldsymbol{F}\left(\boldsymbol{z}\left(N, \varepsilon_{i}\right), N\right)\right\|^{2}\right\}=0 \\
& \lim _{i \rightarrow \infty} \frac{1}{\varepsilon_{i}} \sum_{j=1}^{p_{N}} H\left(g_{i}\left(z\left(N, \varepsilon_{i}\right), N\right)\right)\left(g_{i}\left(z\left(N, \varepsilon_{i}\right), N\right)\right)^{2}=0 \\
& \lim _{i \rightarrow \infty} z\left(N, \varepsilon_{i}^{\prime}\right)=z^{*}(N) \in Z_{N} *
\end{aligned}
$$

ここで， $\left\{\varepsilon_{i}^{\prime}\right\}$ は $\left\{\varepsilon_{i}\right\}$ の適当な部分列で, $Z_{N}{ }^{*}$ は， (5), (6) 式の等式不等式を満足し $S(N) z(N)=0$

*1（7）式を $\varepsilon$ て除した形 $I(z(N), N, \varepsilon) / \varepsilon$ が文献 (8)

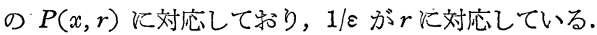

を満足する固定端点問題の解の集合で $z^{*}(N)$ は, $Z_{N}$ * の中で評価 $J(z(N), N))$ を最小化するある解である. もし $Z_{N}$ * に属する要素のらち評価を最小化する解 $\boldsymbol{z}^{*}(N)$ が唯一であれば,

$$
\lim _{i \rightarrow \infty} z\left(N, \varepsilon_{i}\right)=z^{*}(N)
$$

となる。これらの結果に必要な仮定は文献（8）によ り,

A-0 $Z_{N}$ * は空でない. $(S(N) z(N)=0$ も満足 されなければならないから, 最短時間を $N_{\min }$ とすれ ば，この場合は， $N \geqq N_{\min }$ であることを注意して拉 く)

A-1 $J(z(N), N), \quad \boldsymbol{F}(z(N), N), g_{i}(z(N), N)$, $i=1, \cdots, p_{N}$ は $\boldsymbol{z}(N)$ の連続関数であるとし, $J(z(N)$, $N) \geqq 0$ であるとする.

A-2 ある $\varepsilon_{0}$ が存在して, $\varepsilon<\varepsilon_{0}$ ならば， $\min I(z(N), N, \varepsilon)=\inf I(z(N), N, \varepsilon)$

A-3 ある $\delta_{N}>0$ が存在して， $Z_{N \delta}=\left\{\boldsymbol{z}(N) \mid\|S(N) \boldsymbol{z}(N)\| \leqq \delta_{N},\|\boldsymbol{F}(\boldsymbol{z}(N), N)\|\right.$ $\left.\leqq \delta_{N}, g_{i}(z(N), N) \leqq \delta_{N}, i=1, \cdots, p_{N}\right\}$ が有界である。

ここで，仮定 A-1〜A-3 は $N \leqq N \min$ となる $N$ に ついても成り立つとする.

以上の仮定は, 最短時間 $N_{\min }$ より大なる $N$ に対し て行なわれた仮定であるが，最短時間 $N_{\min }$ を求める 立場から必要となる付加的な仮定をして和く。

A-4（2）式の左辺に拉いて, $\boldsymbol{x}(1), \cdots, \boldsymbol{x}(N)$ を（1）式の逗移方程式により消去した場合，（2)式 を満足する $r \times N$ 次元ベクトル $\left(\boldsymbol{u}^{\prime}(0) \cdots \boldsymbol{u}^{\prime}(N-1)\right)^{\prime}$ の集合を $U_{N}$ とすれば， $U_{N}$ は有界であるとする。 この仮定は, 操作量に対する制限とともに状態が制限 されるために操作量が制限をらけることを意味してい る.

この仮定によれば，(1)，(2) 式を満足する， $\boldsymbol{x}(1)$, $\cdots, \boldsymbol{x}(N)$ の集合は，仮定 A-1 により $\boldsymbol{f}(\cdot)$ が，連 続であるから，すべて（1）式により $U_{N}$ の連続写 像となるから，やはりコムパクトである、したがって， (1)，（2）式を満足する $\boldsymbol{z}(N)$ の集合はコンパクト である、これを式であらおせば，

$$
\begin{aligned}
Z_{N} & =\left\{\boldsymbol{z}(N) \mid \boldsymbol{F}(\boldsymbol{z}(N), N)=0, g_{i}(\boldsymbol{z}(N), N) \leqq 0,\right. \\
i & \left.=1, \cdots, p_{N}\right\} .
\end{aligned}
$$

となる. 仮定 A-1 による $J(\boldsymbol{z}(N), N)$ の連続性と, $Z_{N}$ のコンパクト性から, $J(z(N), N)$ は, $Z_{N}$ 上で 有界な最大值をもつから,

$$
J_{\max }(N)=\max _{z(N) \in Z_{N}} J(z(N), N)
$$

と抏くことにする。 また $N \geqq N_{\min }$ のときは，固定端 点問題の解の集合 $Z_{N} *$ は, $Z_{N}$ を用いて, $Z_{N} *=\left\{z(N) \mid z(N) \in Z_{N}, S(N) \boldsymbol{z}(N)=0, N \geqq N_{\min }\right\}$ とかけるから， $Z_{N} * \subset Z_{N}$ であり， $N \geqq N_{\min }$ のとき，

$$
J_{\max }(N) \geqq \max _{z(N) \in Z_{N}} J(\boldsymbol{z}(N), N)
$$

である.また（8）式の数列に执いて，つねに， 


$$
\varepsilon_{1} J_{\max }(N) \leqq \delta_{N}
$$

となるように $\varepsilon_{1}$ を選択するものとする.

以上のような仮定 $\mathrm{A}-0 \sim \mathrm{A}-4$ の成否を一般的に判 定する方法は，いまのところないが，これらの仮定が 成立するような系は多々存在すると思われる。

さて, (7) 式の極值 $z\left(N, \varepsilon_{i}\right)$ の存在は仮定 $\mathrm{A}-3$ および (15) 式により保証されて特り，この極值を利 用して, 最短時間問題の解 $N_{\min }$ 执よびある解 $z^{*}$ $\left(N_{\min }\right)$ を決定する方法について述べる．つぎのよう な整数の集合を考学る。

$$
\begin{gathered}
\Omega_{N}\left(\varepsilon_{i}\right)=\left\{N \mid N \geqq 0, \min I\left(\boldsymbol{z}(N), N, \varepsilon_{i}\right)\right. \\
\left.\left(=I\left(\boldsymbol{z}\left(N, \varepsilon_{i}\right), N, \varepsilon_{i}\right)\right) \leqq \varepsilon_{i} J_{\max }(N)\right\}
\end{gathered}
$$

この整数の集合に捇いて，まず，つぎのような性質が わかる. $N \geqq N_{\min }$ ならば，固定端点問題の解の集合 $Z_{N}$ * の任意の要素 $z_{1}(N)$ は各制限条件を満足するか ら $\left\|S(N) z_{1}(N)\right\|^{2}=0,\left\|\boldsymbol{F}\left(z_{1}(N), N\right)\right\|^{2}=0$, 特よび $\sum_{i=1}^{p_{N}} H\left(g_{i}\left(z_{1}(N), N\right)\right)\left(g_{i}\left(z_{1}(N), N\right)\right)^{2}=0$ であり, 必ずしも $z_{1}(N)$ は $I\left(z(N), N, \varepsilon_{i}\right)$ を最小化しない から,

$$
\begin{aligned}
& I\left(z\left(N, \varepsilon_{i}\right), N, \varepsilon_{i}\right)\left(=\min I\left(z(N), N, \varepsilon_{i}\right)\right) \\
& \quad \leqq I\left(z_{1}(N), N, \varepsilon_{i}\right)=\varepsilon_{i} J\left(z_{1}(N), N\right) \leqq \varepsilon_{i} J_{\max }(N)
\end{aligned}
$$

となる.したがって，(16) 式から，

$$
N \geqq N_{\min } \text { ならば } N \in \Omega_{N}\left(\varepsilon_{i}\right), \quad i=1, \cdots,
$$

がいえる、しかし，逆は必ずしも真ではないことは注 意して扣く.つぎに, $\Omega_{N}\left(\varepsilon_{i}\right), i=1, \cdots$, に招いて, $\varepsilon_{i}>\varepsilon_{i+1}>0$ ならば $\Omega_{N}\left(\varepsilon_{i}\right) \supset \Omega_{N}\left(\varepsilon_{i+1}\right)$ であることを示そう。

【証明】 $\Omega_{N}\left(\varepsilon_{i+1}\right)$ に含まれる任意の要素はすべ て $\Omega_{N}\left(\varepsilon_{i}\right)$ の要素であることを示せばよい. いま $N^{\prime}$ $\in \Omega_{N}\left(\varepsilon_{i+1}\right)$ とすれば，(16) 式から,

$\min I\left(z\left(N^{\prime}\right), N^{\prime}, \varepsilon_{i+1}\right)=I\left(z\left(N^{\prime}, \varepsilon_{i+1}\right), N^{\prime}, \varepsilon_{i+1}\right)$

$$
\leqq \varepsilon_{i+1} J_{\max }\left(N^{\prime}\right)
$$

であり, さらに (17) 式の $I\left(z\left(N^{\prime}\right), N^{\prime}, \varepsilon_{i}\right)$ の第 1 第 3 項がすべて非負であることを考学れば，(20）式 から,

$$
\varepsilon_{i+1} J\left(z\left(N^{\prime}, \varepsilon_{i+1}\right), N^{\prime}\right) \leqq \varepsilon_{i+1} J_{\max }\left(N^{\prime}\right)
$$

となる、いっぽう，(20),(21) 式の不等式と $\varepsilon_{i}-\varepsilon_{i+1}$ $>0$, 抌よび $z\left(N^{\prime}, \varepsilon_{i+1}\right)$ は必ずしも $I\left(z\left(N^{\prime}\right), N, \varepsilon_{i}\right)$ を最小化しないことを考慮すれば,

$$
\begin{aligned}
\min & I\left(z\left(N^{\prime}\right), N^{\prime}, \varepsilon_{i}\right)\left(=I\left(z\left(N^{\prime}, \varepsilon_{i}\right), N^{\prime}, \varepsilon_{i}\right)\right. \\
\leqq & I\left(z\left(N^{\prime}, \varepsilon_{i+1}\right), N^{\prime}, \varepsilon_{i}\right) \\
= & I\left(z\left(N^{\prime}, \varepsilon_{i+1}\right), N^{\prime}, \varepsilon_{i+1}\right) \\
& +\left(\varepsilon_{i}-\varepsilon_{i+1}\right) J\left(z\left(N^{\prime}, \varepsilon_{i+1}\right), N^{\prime}\right) \\
\leqq & \varepsilon_{i+1} J_{\max }\left(N^{\prime}\right)+\left(\varepsilon_{i}-\varepsilon_{i+1}\right) J_{\max }\left(N^{\prime}\right) \\
= & \varepsilon_{i} J_{\max }\left(N^{\prime}\right)
\end{aligned}
$$

となり，(16) 式の定義にしたがって $N^{\prime} \in \Omega_{N}\left(\varepsilon_{i}\right)$ で ある.よって $\Omega_{N}\left(\varepsilon_{i}\right) \supset \Omega_{N}\left(\varepsilon_{i+1}\right)$ が証明された.

この関係を用いれば, (12) 式の $\varepsilon_{i}$ の数列に対して,

$$
\Omega_{N}\left(\varepsilon_{1}\right) \supset \cdots \supset \Omega_{N}\left(\varepsilon_{i}\right) \supset \Omega_{N}\left(\varepsilon_{i+1}\right) \supset \cdots
$$

となるから， $\Omega_{N}\left(\varepsilon_{i}\right)$ に属する整数の最小值を $N^{*}\left(\varepsilon_{i}\right)$ と書くことにすれば，(23) 式から，

$$
N^{*}\left(\varepsilon_{1}\right) \leqq N^{*}\left(\varepsilon_{2}\right) \leqq \cdots \leqq N^{*}\left(\varepsilon_{i}\right) \leqq N^{*}\left(\varepsilon_{i+1}\right) \leqq \cdots
$$

となる.ささらに，(17) 式より任意の $\varepsilon_{i}$ について $N_{\min } \in \Omega_{N}\left(\varepsilon_{i}\right)$ であり, $N^{*}\left(\varepsilon_{i}\right)$ は $\Omega_{N}\left(\varepsilon_{i}\right)$ の最小值 であるから，

$$
N^{*}\left(\varepsilon_{i}\right) \leqq N_{\min }
$$

となる。（24), (25) 式から， $N^{*}\left(\varepsilon_{i}\right)$ は有界な非減少 無限数列で, 有限個 ( $\leqq N_{\min }$ 個) の值しかとらない から，ある整数 $K$ が存在して，

$$
N^{*}\left(\varepsilon_{i}\right)=\tilde{N}\left(\leqq N_{\min }\right), \quad i \geqq K
$$

となる.すなわち,

$$
\tilde{N} \in \bigcap_{i=K}^{\infty} \Omega_{N}\left(\varepsilon_{i}\right)
$$

したがって，(16) 式から， $i \geqq K$ に対して，

$$
I\left(\boldsymbol{z}\left(\tilde{N}, \varepsilon_{i}\right), \tilde{N}, \varepsilon_{i}\right) \leqq \varepsilon_{i} J_{\max }(\tilde{N}) \leqq \varepsilon_{1} J_{\max }(\tilde{N})
$$

となる. 仮定 A-3 によって, $z\left(\tilde{N}, \varepsilon_{i}\right)$ はコンパクト 集合 $Z_{\widetilde{N}}$ の要素であることから， $\varepsilon_{i} ， i \geqq K$ の部分列 $\varepsilon_{i}^{\prime}$ が存在して,

$$
\lim _{i \rightarrow \infty} \boldsymbol{z}\left(\tilde{N}, \varepsilon_{i}\right)=\tilde{\boldsymbol{z}}(\tilde{N})
$$

とすることができる、したがって (27)，(28) 式から，

$$
\begin{gathered}
\lim _{i \rightarrow \infty} I\left(\boldsymbol{z}\left(\tilde{N}, \varepsilon_{i}{ }^{\prime}\right), \tilde{N}, \varepsilon_{i}{ }^{\prime}\right)=I(\tilde{z}(\tilde{N}), \tilde{N}, 0) \\
\leqq \lim _{i \rightarrow \infty} \varepsilon_{i}^{\prime} J_{\max }(\tilde{N})=0
\end{gathered}
$$

となる.（30) 式は，(7) 式から，

$$
\begin{aligned}
& \|S(\tilde{N}) \boldsymbol{z}(\tilde{N})\|^{2}=0, \quad\|\boldsymbol{F}(\tilde{\boldsymbol{z}}(\tilde{N}), N)\|^{2}=0 \\
& g_{i}(\tilde{\boldsymbol{z}}(\tilde{N}), \tilde{N}) \leqq 0, \quad i=1, \cdots, p \widetilde{N}
\end{aligned}
$$

を意味するから，このように，(5)，(6) 式の制限条 件を満足し，原点到達するためには，

$$
\widetilde{N} \geqq N_{\min }
$$

でなければならない、したがって (32)，(26) 式から，

$$
\widetilde{N}=N_{\min }
$$

である. $N=\tilde{N}$ に対しては，(13)〜(15) 式が成り立 ち, 評価 $J(z(\widetilde{N}), \tilde{N})$ を最小化する最短時間問題の. ある解 $z^{*}(\tilde{N})$ に収束する解の列 $z\left(\tilde{N}, \varepsilon_{i}\right), i \geqq K$ を 得る.このように，十分小さな $\varepsilon_{i}$ に対して， $\Omega_{N}\left(\varepsilon_{i}\right)$ の最小值 $N^{*}\left(\varepsilon_{i}\right)$ を求めることにより $N_{\min }$ を求め ることができるのであるが，そのような $\varepsilon_{i}$ の值を理 論的に定めるのは困難であるとともに， $\varepsilon_{i}$ が小さいほ ど精度が高いといっても, 数值解に执いて括もに計算 機の計算精度により $\varepsilon_{i}$ の下限が制限をらけ, 理論的 に $\varepsilon_{i}$ の下限を定めることも困難である．たとえば， 計算精度に関係する例として次のような系特よび制限 を考觉る。

$x(k+1)=x(k)+u(k),|u(k)| \leqq 1, k=0, \cdots, N-1$ ここで, $x(k), u(k)$ はスカラーである.さらに,

$$
J(z(N), N)=\sum_{k=0}^{N-1}(u(k))^{2}
$$

とする: いま, 初期条件を $x(0)=1.5$ とすれば, 
$N_{\min }=2, u^{*}(0)+u^{*}(1)=-1.5$

である.いっぽう（7）式の罰関数は，不等式制限の みを考虑することにすれば,

$$
\begin{aligned}
& I(\boldsymbol{z}(N), N, \varepsilon)=(x(N))^{2}+\sum_{k=0}^{N-1}\{H(u(k)-1) \\
& \left.\quad \times(u(k)-1)^{2}+H(-u(k)-1)(-u(k)-1)^{2}\right\} \\
& \quad+\varepsilon \sum_{k=0}^{N-1}(u(k))^{2}
\end{aligned}
$$

となる. ここで, $x(N)=x(0)+u(0)+\cdots+u(N-1)$ である.いま $N=2$ とすれば, 罰関数の極値解の方程 式は,

となり

$$
\begin{aligned}
& (1+\varepsilon) u(0)+u(1)+1.5=0 \\
& u(0)+(1+\varepsilon) u(1)+1.5=0
\end{aligned}
$$

$$
u(0)=u(1)=-1.5 /(2+\varepsilon)
$$

となる.もらろん，この形で $\varepsilon \rightarrow 0$ とすれば真值を得 られるが，一般には，このよらな解析解を得るのは困 難で，実際には上述の 2 つの方程式を同時に満足する 解を逆行列等を用いて数值的に求める必要がある. こ の場合に， $\varepsilon$ の值が 1 に比べて計算機の有効けた数以 下に小さい場合は, 計算機の演算に括いて, $1+\varepsilon=1$ となるので，上述の連立方程式がたがいに独立ではな くなり, 逆行列を用いる求解は不可能になる.

しかしながら，普通の大形計算機に特いては，単精 度計算で有効けた数は約 7 けた程度であり,かりに $=10^{-6}$ とすれば,

$$
u(0)=u(1)=-0.7499996
$$

いっぽら，最短時間解のらち $J(\boldsymbol{z}(2), 2)=(u(0))^{2}+$ $(u(1))^{2}$ を最小化する真の解は，

$$
u(0)=u(1)=-0.75
$$

である.このように，適当なとの選択により，逆行列 の存在を保証でさるとともに，単精度計算によっても， 評価を最小にする最適解に十分近い近似解を得ること ができることは，本方法の大きな利点と思われる．

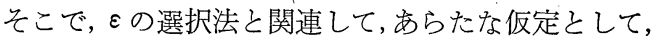

$$
\begin{aligned}
& N \leqq N_{\min } \\
& \|S(N) \boldsymbol{z}(N)\|^{2} \leqq \gamma_{1}, \gamma_{1}>0 \\
& \|\boldsymbol{F}(\boldsymbol{z}(N), N)\|^{2} \leqq \gamma_{2}, \gamma_{2}>0 \\
& g_{j}(z(N), N) \leqq \gamma_{3}, j=1, \cdots, p_{N}, \gamma_{3}>0
\end{aligned}
$$

を満たせば，すべて最短時間問題の近似解であるとす る. ここに $\gamma_{1}, r_{2}, r_{3}$, は, 物理的考察から与えられ る許容誤差である.すなわち，(34）式を満足するこ とは，最短時間 $N_{\min }$ 以下の時間で原点の近傍に到達

*2 仮定A-4に尔いて, $I_{\max }(N)$ の值または $M(N)>J_{\max }$ $(N)$ となる $M(N)$ が容易に得られるように $J(z(N)$, $N)$ を決定されているものとする.たと充ば, $\left|u^{i}(k)\right| \leqq 1$, $i=1, \cdots, r, k=0, \cdots, N-1$ の場合には, $J\left(z(N), N=\sum_{i=0}^{N-1}\right.$ $\|\boldsymbol{u}(k)\|^{2}$ ，とすれば， $J_{\max }(N)=r N$ である. また，有 限值 $M(N)$ が与兄られる場合には，これを $J_{\max }(N)$ の代わりに用いても，理論的に支障のないことはあき らかである。

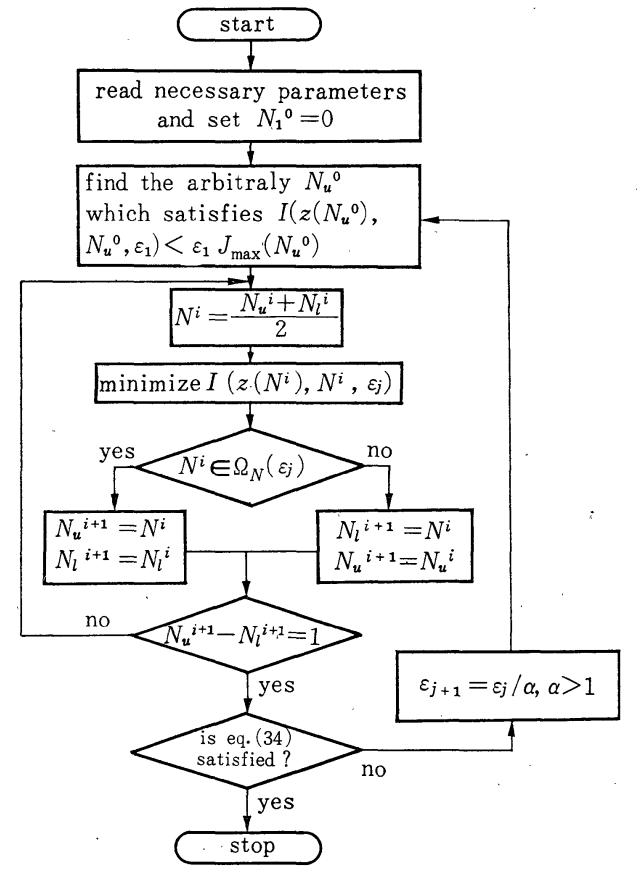

Fig. 1 Flow chart of the algorithm which solves the minimum-time problems

できることを意味する．このような近似解を求める一 方法として, $\Omega_{N}\left(\varepsilon_{i}\right)$ に含まれる各 $N$ について睘関数 の極值 $z\left(N, \varepsilon_{i}\right)$ が (16) 式を満足することに着目し て, $N^{*}\left(\varepsilon_{i}\right) \leqq N \leqq N_{\min }$ となる $N$ を求めつつ, $\boldsymbol{z}(N$, $\left.\varepsilon_{i}\right)$ が (34) 式を満足するまで $\varepsilon_{i}$ を小さくしていく 方法が考学られる，以下に，近似解を求めるアルゴリ ズムの例特よび収束について述べる.

(i ) $\varepsilon_{1}>0$ ，を与え $\boldsymbol{z}\left(N_{u}{ }^{0}, \varepsilon_{1}\right)$ を計算しつつ, $I\left(z\left(N_{u}^{0}, \varepsilon_{1}\right), N_{u}^{0}, \varepsilon_{1}\right) \leqq \varepsilon_{1} J_{\max }\left(N_{u}{ }^{0}\right) * 2$

となる $N_{u}{ }^{0}$ を見つける。 また最初は $N_{l}{ }^{0}=0$ と拈く。

(ii) $N^{i}=\left(N_{u}^{i}+N_{l}^{i}\right) / 2$ と特いて, $z\left(N^{i}, \varepsilon_{j}\right)$ 特 よび $I\left(\boldsymbol{z}\left(N^{i}, \varepsilon_{j}\right), N^{i}, \varepsilon_{j}\right)$ を求める.

(iii）（16）式によって, $N_{u}^{i}, N_{l}^{i}$, $N^{i} \in \Omega_{N}\left(\varepsilon_{j}\right)$ ならば $N_{u}^{i+1}=N^{i}, N_{l}^{i+1}=N_{l}^{i}$ $N^{i} \notin \Omega_{N}\left(\varepsilon_{j}\right)$ ならば $N_{u}^{i+1}=N_{u}^{i}, \quad N_{u}^{i+1}=N_{u}^{i}$ と修正し， $N_{u}^{i+1}-N_{l}^{i+1}>1$ ならば（ii）の計算にも ぞる.

(iv) $N_{u}^{i+1}-N_{l}^{i+1}=1$ ならば，(34) 式によって， 与えられた許容䛊差の範囲内かぞうか検討し，(34)式 が満足される場合は計算を終了し, 満足されない場合 は, $\varepsilon_{j+1}=\varepsilon_{j} / \alpha, \alpha>1$ 和よび $N_{l}^{0}=N_{l}^{i+1}$ として， (i) の計算にもどる.

このアルゴリズムのフローチャートを Fig. 1 に示 す.このアルゴリズムからあきらかなように，

$$
N_{u}^{i+1}-N_{l}^{i+1}=\left(N_{u}^{i}-N_{l}^{i}\right) / 2 \mid
$$

（小数以下切捨または切上）

であるから，アルゴリズム（ii)，(iii）の繰返しによ 
り有限回で $N_{u}^{i+1}-N_{l}^{i+1}=1$ となる. $N_{u}^{i+1} \in \Omega_{N}$ $\left(\varepsilon_{j}\right), N_{l}^{i+1} \oplus \Omega_{N}\left(\varepsilon_{j}\right)$ であるから， $N_{u}^{i+1}-N_{l}^{i+1}=1$ となる $N_{u}^{i+1}$ について，

$$
N_{u}{ }^{i+1} \in \Omega_{N}\left(\varepsilon_{j}\right) \& N_{u}^{i+1}-1 \notin \Omega_{N}\left(\varepsilon_{j}\right)
$$

となる. $N^{*}\left(\varepsilon_{j}\right)$ が $\Omega_{N}\left(\varepsilon_{j}\right)$ の最小値であること, 特 よび $N_{u}^{i+1}>N_{\min }$ ならば (36) 式のよらなことは起 こらないことを考虑すれば，（36）式が成立するよう な $N_{u}^{i+1}$ は,

$$
N^{*}\left(\varepsilon_{j}\right) \leqq N_{u}^{i+1} \leqq N_{\min }
$$

である.したがって，このよらな $N_{u}^{i+1}$ に対して， $z\left(N_{u}{ }^{i+1}, \varepsilon_{j}\right)$ が (34) 式を満足するならば, これが最 短時間問題の近似解となる.

$$
\begin{aligned}
& \text { また, (7), (16) 式から, } \\
& \left\|S\left(N_{u}^{i+1}\right) \boldsymbol{z}\left(N_{u}^{i+1}, \varepsilon_{j}\right)\right\|^{2}+\left\|\boldsymbol{F}\left(\boldsymbol{z}\left(N_{u}{ }^{i+1}, \varepsilon_{j}\right), N_{u}^{i+1}\right)\right\|^{2} \\
& +\sum_{u_{u}^{i+1}} H\left(g_{i}\left(\boldsymbol{z}\left(N_{u}^{i+1}, \varepsilon_{j}\right), N_{u}^{i+1}\right)\right) \\
& \times\left(g_{i}\left(\boldsymbol{z}\left(N_{u}^{i+1}, \varepsilon_{j}\right), N_{u}^{i+1}\right)\right)^{2} \leqq \varepsilon_{j \max } J\left(N_{u}^{i+1}\right)
\end{aligned}
$$

であるから，ある $\varepsilon_{j}$ に対して (34) 式を満足する $z\left(N_{u}{ }^{i+1}, \varepsilon_{j}\right)$ の存在が保証される.

また，解が存在しない場合には，（5)，(6) 式の等 式特よび不等式制限条件和よび原点到達を同時に満足 する解は存在しないから，（7）式に和いて，をを零 としても,

$$
\min I(\boldsymbol{z}(N), N, 0)>0
$$

となる。したがって， $\varepsilon_{\imath} \rightarrow 0$ とするとき，

$$
I\left(\boldsymbol{z}\left(N, \varepsilon_{i}\right), N, \varepsilon_{i}\right) \geqq I\left(\boldsymbol{z}\left(N, \varepsilon_{i}\right), N, 0\right)>\varepsilon_{i} J_{\max }(N)
$$
となり，アルゴリズムの (i ) に拈いて $N_{u}{ }^{0} \rightarrow \infty$ とな りアルゴリズムが収束しなくなる.

\section{3. $z\left(\boldsymbol{N}, \varepsilon_{i}^{\mathrm{E}}\right)$ の計算法}

これまで, 各 $\varepsilon_{i}$ に対する罚関数 $I\left(z(N), N, \varepsilon_{i}\right)$ の極值 $\boldsymbol{z}\left(N, \varepsilon_{i}\right)$ が計算され得るものとして理論を尊 びいてきたが，一般に $I\left(\boldsymbol{z}(N), N, \varepsilon_{i}\right)$ の極值はこう 配法など6,7)により求める必要があり, 計算法の収束 の速さなどが問題となる。ここでは， $I\left(z(N), N, \varepsilon_{i}\right)$ のように, ヘビサイドのステップ関数を含むような関 数の極值探索に適していると思われる計算法について 述べる。とくに等式制限物よび不等式制限が線形であ る場合に，この計算法は有用である.

説明の簡単のため, $I\left(z(N), N, \varepsilon_{i}\right)$ を簡単化し，

$$
I(\boldsymbol{z})=I_{1}(\boldsymbol{z})+\sum_{i=1}^{p} H\left(h^{i}(\boldsymbol{z})\right)\left(h^{i}(\boldsymbol{z})\right)^{2}
$$

に执きか劣考察する，ここで， $I_{1}(\boldsymbol{z})$ および $h^{i}(\boldsymbol{z})$ はヘビサイドのステップ関数を含まない連続関数で,

*3 $N \geqq N^{*}\left(\varepsilon_{j}\right)$ ならば $N \in \Omega_{N}\left(\varepsilon_{j}\right)$ が成立するならば (36) 式を満足する $N_{u}{ }^{i+1}$ は $N^{*}\left(\varepsilon_{j}\right)$ のみであるが, たとえば, $\Omega_{N}\left(\varepsilon_{j}\right)=\{5,6,8,9,10, \cdots\}$ のよ5な集合の 場合には，(36) 式を満足する $N_{u}{ }^{i+1}$ は， $5\left(=N^{*}\left(\varepsilon_{j}\right)\right)$ のみならず, $7 \in \Omega_{N}\left(\varepsilon_{j}\right)$ であるため, 8 も (36) 式を 満足することになり，一般にこのような $N_{u}{ }^{i+1}$ は唯一 ではない。
連続な 2 階の導関数をもつとする。もちろん，(39) 式に直接こう配法を適用しても極值を得ることができ るが，以下のように，(39) 式の $I(z)$ をへビサイド のステップ関数を含まない関数に执きかえて極值を計 算することを考える。

（i） 初期値の設定 任意に $\alpha_{i}{ }^{0}, 0 \leqq \alpha_{i}{ }^{0} \leqq 1$, $i=1, \cdots, p$ を選ぶ.

(ii) 極值探索 (39) 式のへビサイドのステッ プ関数 $H\left(h^{i}(z)\right)$ のかわりに $\alpha_{i}^{j}$ と招いた関数,

$$
\begin{aligned}
I^{*}\left(\boldsymbol{z}, \boldsymbol{\alpha}^{j}\right) & =I_{1}(\boldsymbol{z})+\sum_{i=1}^{p} \alpha_{i}^{j}\left(h^{i}(z)\right)^{2}, \\
\boldsymbol{\alpha}^{j} & =\left(\alpha_{1}^{j}, \cdots, \alpha_{p}{ }^{j}\right)
\end{aligned}
$$

の極值 $z^{j}$ をこう配法などにより求める.

(iii) 収束の吟味 $z^{j}$

$$
H\left(h^{i}\left(\boldsymbol{z}^{j}\right)\right)=\alpha_{i}^{j}, \quad i=1, \cdots, p
$$

または，

$$
\left\|\partial I\left(\boldsymbol{z}^{j}\right) / \partial \boldsymbol{z}\right\|^{2}<\delta^{*}, \delta^{*}>0
$$

を満足するならば，収束したとする。

(iv) $\alpha_{i}^{j}$ の修正 $z^{j}$ が（iii）の収束の条件を满 足しない場合は， $\alpha_{i}^{j}$ をあらたに，

$$
\alpha_{i}^{j+1}=\alpha_{i}^{j}+\beta^{j}\left(H\left(h^{i}\left(z^{j}\right)\right)-\alpha_{i}^{j}\right), \quad i=1, \cdots, p
$$

と修正する。ここで， $\beta^{j}$ は， $H\left(h^{i}\left(\boldsymbol{z}^{j}\right)\right) \neq \alpha_{i}^{j}$ ならば, $\beta^{j}=\min \left\{1, \delta /\left|H\left(h^{i}\left(z^{j}\right)\right)-\alpha_{i}{ }^{j}\right|, \quad i=1, \cdots, p\right\}$

である. $\left(H\left(h^{i}\left(z^{j}\right)\right)=\alpha_{i}^{j}\right.$ ならば修正は行なわない。 この修正後（ii）の計算にもどり，（iii）の収束の条件 が満足されるまで，この過程を繰返す。

(iii) の收束の条件のうち, (41) 式は,

$$
\begin{aligned}
& \frac{\partial I^{*}\left(\boldsymbol{z}^{j}, \alpha^{j}\right)}{\partial \boldsymbol{z}}=0=\frac{\partial I_{1}\left(\boldsymbol{z}^{j}\right)}{\partial \boldsymbol{z}}+\sum_{i=1}^{p} \alpha_{i}{ }^{j} \frac{\partial\left(h^{i}\left(\boldsymbol{z}^{j}\right)\right)^{2}}{\partial \boldsymbol{z}} \\
& =\frac{\partial I_{1}\left(\boldsymbol{z}^{j}\right)}{\partial \boldsymbol{z}}+\sum_{i=1}^{p} H\left(h^{i}\left(\boldsymbol{z}^{j}\right)\right) \frac{\partial\left(h^{i}\left(\boldsymbol{z}^{j}\right)\right)^{2}}{\partial \boldsymbol{z}}=\frac{\partial I\left(\boldsymbol{z}^{j}\right)}{\partial \boldsymbol{z}}
\end{aligned}
$$

となり， $z^{j}$ は $I(z)$ の極值と一致することがわかる. また（42）式は一般の収束判定の意味である，このア ルゴリズムは, 前述のように, とくに $I_{1}(z)$ が $z$ の 2 次までの関数で, $h^{i}(z)$ が $z$ の 1 次の関数である場 合に有用である。すなわちこの場合には， $I(z)$ がへ

*4, *5 ヘビサイドのステップ関数 $H(\cdot)$ は, 不連続関数で あるが， $f(x)=H(x) x^{2}$ なる関数は， $H(x)$ の不連続点 $x=0$ に和いても，1階連続微分可能で， $f^{\prime}(0)=\left.2 H(x) x\right|_{x-0}=0$

であり，さらに，この点において，2階微分は有界で左 微分係数は 0 ，右微分係数は 2 である. したがって， $x=0$ の近傍に竹けるテーラー展開は， 2 次の項で打切 $\triangleright \tau$,

$$
\begin{aligned}
& f(x)=f(0)+f^{\prime}(0) x+(1 / 2) f^{\prime \prime}(0)(\theta x)^{2}, 0 \leqq \theta \leqq 1 \\
&=(1 / 2) f^{\prime \prime}(0)(\theta x)^{2} \\
& \text { ここで, } \cdot \theta=1, \\
& f^{\prime \prime}(0)=\left\{\begin{array}{lll}
x \geqq 0 & \text { ならば } & 2 \\
x<0 & \text { ならば } & 0
\end{array}\right.
\end{aligned}
$$

となる. $x \neq 0$ では, $H(x)$ は定係数となるから問題は ない. 
ビサイドのステップ関数によるステップ状の非線形性 を有するのに対して, $I^{*}\left(z, \alpha^{j}\right)$ は単に $z$ の 2 次関数 であり，後述するように，D.P. 法などにより容易に 極值の計算ができる。 また一般の場合に执いても， $I(z)$ よりも, ステップ状の非線形性をもたない $I^{*}(z$, $\left.\boldsymbol{\alpha}^{j}\right)$ の極值が容易に求められる場合には，このアルゴ リズムは有用と思われる.

このアルゴリズムの収束を無条件で証明するのは困 難であるが, $I^{*}\left(z, \alpha^{j}\right)$ の極值が求まるものとし， $I_{1}$ (z) 特よび $\left(h^{i}(z)^{2}, i\right)^{2}=1, \cdots, p$ が円で連続な 2 階導 関数をもつ場合には, 以下のよらにして証明できる. まず $j$ 回の繰返しにより得られた $I^{*}\left(z, \alpha^{j}\right)$ の極值 $\boldsymbol{z}^{j}$ が収束の条件 (41)，(42）式を満足しないとする. すなおち， $m$ 個の $i$ に対して，

$$
\begin{aligned}
& H\left(h^{i}\left(\boldsymbol{z}^{j}\right)\right) \neq \alpha_{i}{ }^{j}, \quad i=i_{1}, \cdots, i_{m} \\
& \left\|\partial I\left(\boldsymbol{z}^{j}\right) / \partial \boldsymbol{z}\right\|^{2}>\delta^{*}
\end{aligned}
$$

であるとすれば，(43) 式の $\alpha$ の修正によりあらたに 得られる $I^{*}\left(z, \alpha^{j+1}\right)$ の極值 $z^{j+1}$ 、対して, (44) 式 の $\delta$ を適当に選ぶことにより,$I\left(z^{j+1}\right)<I\left(z^{j}\right)$ となる ことを示す、いま，

$$
\Delta z^{j}=z^{j+1}-z^{j}
$$

とし， $z^{j}$ のまわりで $I(z)$ をテーラー展開することに より,

$$
I\left(\boldsymbol{z}^{j+1}\right)=I\left(\boldsymbol{z}^{j}\right)+\left(\partial I\left(\boldsymbol{z}^{j}\right) / \partial z\right)^{\prime} \Delta \boldsymbol{z}^{j}+o\left(\Delta z^{j}\right)
$$

と書くことができる. いっぽう $z^{j}$ が $I^{*}\left(z, \alpha^{j}\right)$ の極 值であることを考学れば， $z^{j}$ が $\partial I^{*}\left(z^{j}, \alpha^{j}\right) / \partial z=0$ な る方程式により関係づけられるので,

$$
\begin{aligned}
& \boldsymbol{z}^{j+1}=\boldsymbol{z}^{j}+\sum_{i=1}^{p}\left(\partial \boldsymbol{z}^{j} / \partial \alpha_{i}^{j}\right) \Delta \alpha_{i}^{j}+o\left(\Delta \alpha^{j}\right) \\
& \left.\begin{array}{c}
\Delta \alpha_{i}{ }^{j}=\alpha_{i}{ }^{j+1}-\alpha_{i}{ }^{j}=\beta^{j}\left(H\left(h^{i}\left(z^{j}\right)\right)-\alpha_{i}{ }^{j}\right), \\
\Delta \boldsymbol{\alpha}^{j}=\left(\Delta \alpha_{i}{ }^{j}, \cdots, \Delta \alpha_{p}{ }^{j}\right)^{\prime}
\end{array}\right\}
\end{aligned}
$$

扣よび，陰関数の定理により，

$$
\begin{aligned}
& \frac{d}{d \alpha_{i}}\left(\frac{\partial I^{*}\left(z^{j}, \alpha^{j}\right)}{\partial z}\right)=\frac{\partial^{2} I^{*}\left(z^{j}, \alpha^{j}\right)}{\partial z^{2}} \frac{\partial z^{j}}{\partial \alpha_{i}} \\
& \quad+\frac{\partial\left(h^{i}\left(z^{j}\right)\right)^{2}}{\partial z}=0 \\
& \quad i=1, \cdots, p
\end{aligned}
$$

なる関係がある。仮定により， $I^{*}\left(z, \alpha^{j}\right)$ は, $z$ につ いて凸であるから， $\partial^{2} I^{*}\left(z^{j}, \alpha^{j}\right) / \partial z^{2}$ は正定值行列で あり，これを $S_{j}^{*}$ ，と書くことにすれば，(51) 式より， $\partial z^{j} / \partial \alpha_{i}=-S_{j}^{*-1} \cdot \partial\left(h^{i}\left(\boldsymbol{z}^{j}\right)\right)^{2} / \partial \boldsymbol{z}, \quad i=1, \cdots, p$

となる。（52）式を（50）式に代入すれば,

$$
\begin{aligned}
\Delta z^{j} & =z^{j+1}-z^{j}=-S_{j}{ }^{*-1} \sum_{i=1}^{p}\left(\partial\left(h^{i}\left(z^{j}\right)\right)^{2} / \partial z\right) \cdot \Delta \alpha_{i}^{j} \\
& +o\left(\Delta \alpha^{j}\right)
\end{aligned}
$$

となる、また，(39)，（40）式から，

$$
I(\boldsymbol{z})=I^{*}(\boldsymbol{z}, \boldsymbol{\alpha})+\sum_{i=1}^{\boldsymbol{p}}\left(H\left(h^{i}(\boldsymbol{z})\right)-\boldsymbol{\alpha}_{i}\right) \cdot\left(h^{i}(\boldsymbol{z})\right)^{2}
$$

であること， $z^{j}$ が $\partial I^{*}\left(z^{j}, \alpha^{j}\right) / \partial z=0$ を満足すること を考慮すれば,

$$
\partial I\left(\boldsymbol{z}^{j}\right) / \partial z=\sum_{i=1}^{p}\left(H\left(h^{i}\left(\boldsymbol{z}^{j}\right)\right)-\alpha_{i}^{j}\right)\left(\partial\left(h^{i}\left(\boldsymbol{z}^{j}\right)\right)^{2} / \partial \boldsymbol{z}\right)
$$

となる.（47）式を考慮すれば, (50) 式の $\Delta \alpha_{i}^{j}$ の式 子(44) 式から,

$$
\left|\Delta \alpha_{i}^{j}\right| \leqq \delta
$$

であるから，(53) 式から $\delta \rightarrow 0$ に対して $\Delta z \rightarrow 0$ であ り，十分小さな $\delta$ に対して (49) 式の第 3 項执よび (53) 式の第 2 項は無視できる. このような条件のも とに（53）式と（55）式を（49）式に代入すれば,

$$
I\left(z^{j+1}\right)-I\left(z^{j}\right) \simeq-\beta^{j} \boldsymbol{h}_{j}{ }^{\prime} S_{j}^{*-1} \boldsymbol{h}_{j}
$$

となる. ここで,

$$
\boldsymbol{h}_{j}=\partial I\left(\boldsymbol{z}^{j}\right) / \partial z
$$

である． $S_{j}^{*-1}$ が正定值であるから，(57) 式から，

$$
I\left(z^{j+1}\right)<I\left(z^{j}\right)
$$

となり， $I(z)$ の凸関数性より, $j \rightarrow \infty$ に対して, $I(z)$ の極值（ $z^{*}$ と書く）に収束する.したがって，

$$
h^{i}\left(z^{*}\right) \neq 0
$$

となる $i$ に対しては, ある整数Kに対して，

$$
\left\|\boldsymbol{z}^{*}-\boldsymbol{z}^{k}\right\|<\mu, \quad k>K
$$

となるから，

$$
H\left(h^{i}\left(z^{*}\right)\right)=H\left(h^{i}\left(z^{k}\right)\right), \quad k \geqq K
$$

となり，(43）式の $\boldsymbol{\alpha}$ の修正法により，十分大きな $k$ に対して,

$$
H\left(h^{i}\left(z^{*}\right)\right)=H\left(h^{i}\left(z^{k}\right)\right)=\alpha_{i}^{k}
$$

となる.すべての $i$ につい（60）式が成立するなら， (45) 式から， $z^{k}=z^{*}$ であるが，

$$
h^{i}\left(z^{*}\right)=0
$$

となる $i$ が存在する場合には, 計算誤差なども関係し て，一般に $H\left(h^{i}\left(z^{k}\right)\right)=\alpha_{i}^{k}$ は期待できないが，(59) 式から，十分大きな $k$ に対して (42) 式が成立するこ とがわかる.よって収束が証明された。

つぎに，特別な場合として，系物よび不等式条件が 線形である場合には，評価 $J(\boldsymbol{z}(N), N)$ を，

$$
\begin{aligned}
& J(\boldsymbol{z}(N), N)=\sum_{k=1}^{N}\left\{\boldsymbol{x}^{\prime}(k) Q(k) \boldsymbol{x}(k)\right. \\
& \left.\left.\left.+\boldsymbol{u}^{\prime}(k-1) \Lambda(k) \boldsymbol{u}(k)\right\}, \theta(k), \Lambda\right) k\right), \\
& \quad \text { 正定值行列 }
\end{aligned}
$$

と和くことによって，（7）式の評価は,

$$
\begin{aligned}
& I(z(N), N, \varepsilon)=\boldsymbol{z}^{\prime}(N)(A(N)+\varepsilon B(N)) \boldsymbol{z}(N) \\
& \quad+\sum_{i=1}^{p_{N}} H\left(z^{\prime}(N) \cdot \boldsymbol{g}^{i}(N)+b^{i}(N)\right)\left(z^{\prime}(N) \boldsymbol{g}^{i}(N)\right. \\
& \left.\quad+b^{i}(N)\right)^{2}
\end{aligned}
$$

の形に書くことができる.ここに $A(N)$ は, $(7)$ 式 の第 1 項と第 2 項をまとめた正定值行列であり， $B$ （N）は，(65）式を（7）式に代入した形でやはり正 定值行列で, $\boldsymbol{g}^{i}(N), b^{i}(N)$ は, 不等式制限の超平面 をあらわすべクトル特よびスカラーである. 簡単のた め，Nとをを固定すれば，(66）式は， 


$$
I(\boldsymbol{z})=\boldsymbol{z}^{\prime} S \boldsymbol{z}+\sum_{i=1}^{p} H\left(\boldsymbol{z}^{\prime} \boldsymbol{g}^{i}+b^{i}\right)\left(\boldsymbol{z}^{\prime} \boldsymbol{g}^{i}+b^{i}\right)^{2}
$$

と書けるから，(40) 式にしたがえば，

$$
\begin{aligned}
I^{*}\left(\boldsymbol{z}, \boldsymbol{\alpha}^{j}\right) & =\boldsymbol{z}^{\prime} S \boldsymbol{z}+\sum_{i=1}^{p} \boldsymbol{\alpha}_{i}^{j}\left(\boldsymbol{z}^{\prime} \boldsymbol{g}^{i}+b^{i}\right)^{2} \\
& =\boldsymbol{z}^{\prime} S_{j}{ }^{*} \boldsymbol{z}+2 \boldsymbol{g}^{\prime} \boldsymbol{z}+c
\end{aligned}
$$

である.ここで,

$$
\begin{aligned}
S_{j}^{*} & =S+\sum_{i=1}^{p} \alpha_{i}^{j} \boldsymbol{g}^{i} \mathbf{g}^{i \prime}, \quad \boldsymbol{g}^{\prime}=\sum_{i=1}^{p} \alpha_{i}^{j} b^{i} \mathbf{g}^{i} \\
c & =\sum_{i=1}^{p} \alpha_{i}^{j}\left(b^{i}\right)^{2}
\end{aligned}
$$

である、したがって

$$
z^{j}=-S_{j}^{*-1} g
$$

となり，上述のアルゴリズムの適用が容易であること がわかる。（43）式に执いて， $\beta^{j}=1$ と执けば，

$$
\alpha_{i}^{j+1}=H\left(z^{j \prime} \boldsymbol{g}^{i}+b^{i}\right)
$$

となるから，この場合には，上述のアルゴリズムは，

(67) の極值を多次元ニュートン法により求めること に一致するから，この場合には、ニュートン法を含ん だアルゴリズムであることがわかる.

さらに特別な場合として, 系がスカラー操作量をも ち,

$$
\boldsymbol{x}(k+1)=\Phi(k) \boldsymbol{x}(k)+\boldsymbol{d}(k) u(k), \quad k=0, \cdots, N-1
$$

であらわされ，不等式の制限条件が，

$$
\begin{gathered}
\boldsymbol{a}^{i \prime} \boldsymbol{x}(k)+b^{i} \leqq 0, \quad i=1, \cdots, m, \quad k=1, \cdots, N \\
|u(k)| \leqq 1, \quad k=0, \cdots, N-1
\end{gathered}
$$

である場合，評価 $J(\boldsymbol{z}(N), N)$ として，

$$
\begin{aligned}
& J(\boldsymbol{z}(N), N)=\sum_{k=1}^{N}\{\boldsymbol{x}(k) Q(k) \boldsymbol{x}(k) \\
& \left.+\lambda(k-1)(u(k-1))^{2}\right\}
\end{aligned}
$$

とすれば，終端点亡不等式制限条件のみ含めた罰関数，

$$
\begin{aligned}
I(\boldsymbol{z}) & =\|\boldsymbol{x}(N)\|^{2}+\sum_{k=1}^{N}\left\{\sum _ { i = 1 } ^ { m } H ( \boldsymbol { a } ^ { i \prime } \boldsymbol { x } ( k ) + b ^ { i } ) \left(\boldsymbol{a}^{i \prime} \boldsymbol{x}(k)\right.\right. \\
& \left.+b^{i}\right)^{2}+H(u(k-1)-1)(u(k-1)-1)^{2} \\
& +H(-u(k-1)-1)(u(k-1)+1)^{2} \\
& +\varepsilon \sum_{k=1}^{N}\left\{\boldsymbol{x}^{\prime}(k) Q(k) \boldsymbol{x}(k)+\lambda(k-1)(u(k-1))^{2}\right\}
\end{aligned}
$$

を設定して，D.P. 法を併用すれば，上述のアルゴリ ズムに括ける罰関数 $I^{*}\left(z, \alpha^{j}\right)$,

$$
\begin{aligned}
& I^{*}\left(\boldsymbol{z}, \boldsymbol{\alpha}^{j}\right)=\|\boldsymbol{x}(N)\|^{2}+\sum_{k=1}^{N}\left\{\sum_{i=1}^{m} \alpha_{x k i}{ }^{j}\left(\boldsymbol{a}^{i \prime} \boldsymbol{x}(k)+b^{i}\right)^{2}\right. \\
& \left.\quad+\alpha_{1 k-1}(u(k-1)-1)^{2}+\alpha_{-1, k-1}(u(k-1)+1)^{2}\right\} \\
& \quad+\varepsilon \sum_{k=1}^{N}\left\{\boldsymbol{x}(k) Q(k) \boldsymbol{x}(k)+\lambda(k-1)(u(k-1))^{2}\right\}
\end{aligned}
$$

の極值 $\boldsymbol{z}^{j}$ はつぎのようにして求まる.すなわら，こ の場合には，D.P. 法を直接適用することにより，

$$
u(k)=B(N-k) \boldsymbol{x}(k)+\theta(N-k), k=0, \cdots, N-1,
$$

なる形で解を得ることができる11).ここで， $B(N-k)$ ， $\theta(N-k)$ は, 行列の繰返し形で与えられ, 以下に結
果のみを記す。

$$
\begin{aligned}
& P(0)=\boldsymbol{I}(n \times n \text { 単位行列 }) \\
& L(0)=0(1 \times n \text { 零行列 }) \\
& S(N-\overline{k+1})=P(N-\overline{k+1})+\sum_{i=1}^{m} \alpha_{x k+1 i} \boldsymbol{a}^{i} \boldsymbol{a}^{i \prime} \\
& +\varepsilon Q(k+1) \\
& L^{*}(N-\overline{k+1})=L(N-\overline{k+1})+\sum_{i=1}^{m} \alpha_{x k+1 i} b^{i} \boldsymbol{a}^{i \prime} \\
& \gamma(k)=\boldsymbol{d}^{\prime}(k) S(N-\overline{k+1}) \boldsymbol{d}(k)+\alpha_{+1 k^{j}}+\alpha_{-1 k^{j}} \\
& +\varepsilon \lambda(k) \\
& B(N-k)=-\gamma^{-1}(k) \boldsymbol{d}^{\prime}(k) S(N-\overline{k+1}) \Phi(k) \\
& \theta(N-k)=-\gamma^{-1}(k)\left(L^{*}(N-\overline{k+1}) \boldsymbol{d}(k)-\alpha_{+1 k^{j}}\right. \\
& \left.+\alpha-1 k^{j}\right) \\
& P(N-k)=\Phi^{\prime}(k) S(N-\overline{k+1}) \Phi(k) \\
& -\gamma(k) B^{\prime}(N-k) B(N-k) \\
& L(N-k)=L^{*}(N-\overline{k+1}) \Phi(k) \\
& \quad+\gamma(k) \theta(N-k) B(N-k)
\end{aligned}
$$

この (78) の一連の式は, $P(0), L(0)$ より, $S(0)$, $L^{*}(0), \gamma(N-1)$ を計算して $B(1), \theta(1)$, を求め, $P(1), L(1)$ の計算に至るような繰返し形計算であり, この計算によって, 操作量が閉ループ形で求まる特長 がある。

\section{4. 例 題}

例題として，つぎのような最短時間問題の解の例を 示す. 系は, 純慣性系,

$$
\boldsymbol{x}(k+1)=\left[\begin{array}{ll}
1 & 1 \\
0 & 1
\end{array}\right] \boldsymbol{x}(k)+\left[\begin{array}{c}
\frac{1}{2} \\
1
\end{array}\right] u(k), \boldsymbol{x}(0)=\left[\begin{array}{c}
10 \\
0
\end{array}\right]
$$

であるとし，不等式制限条件は，

$$
\begin{aligned}
& -[0.1] \boldsymbol{x}(k)-2 \leqq 0, \quad k=1, \cdots, \cdots \\
& |u(k)| \leqq 1, \quad k=0, \cdots, \cdots
\end{aligned}
$$

である. 評価 $J(\boldsymbol{z}(N), N)$ としては，

$$
J(z(N), N)=\sum_{k=0}^{N-1}(u(k))^{2}
$$

と選び，また，不等式制限に対する許容誤差 ((34)式) についてはとくに設定せず, ここでは $\varepsilon=1 / 6 \sim 1 / 6^{8}$ の 8 と和りについて $N^{*}(\varepsilon)$ の計算を行なった（この場 合, (36) 式を満足するのは $N^{*}(\varepsilon)$ のみである). こ の結果,

$$
N^{*}(1 / 6)=6, N^{*}\left(1 / 6^{2}\right)=\cdots N^{*}\left(1 / 6^{8}\right)=7
$$

であり, $\varepsilon=1 / 6^{8}$ に対応する状態值および操作量は

Table 1, 位相軌道は Fig. 2 のと括りである. 各不等 式制限条件はほ泟満足されて和り, 真の解 (Table 2) に十分近いことがわかる。 また，使用計算機は，FA COM 230-60 で，極值計算に拉ける $\boldsymbol{\alpha}^{j}$ の修正式 (43) 式に招いて $\beta^{j}=1$ とした場合， $z^{j}$ の計算時間 は約 0.065 秒で, 数回の繰返しで $z^{*}\left(=z\left(N, \varepsilon_{i}\right)\right)$ を 得ることができ, 上述の 8 と括りの $N^{*}(\varepsilon)$ を求める 時間は全部で約 2.30 秒であった。 
Table 1 Numerical solution of the minimum-time problem of the example by means of the algorithm shown in this paper

\begin{tabular}{c|l|c|c}
\hline $\begin{array}{c}\text { time } \\
k\end{array}$ & \multicolumn{1}{|c|}{$x^{1}(k)$} & $x^{2}(k)$ & $u(k)$ \\
\hline 0 & 10 & 0 & -1.000004 \\
1 & 9.499998 & -1.000004 & -0.999997 \\
2 & 7.999996 & -2.000000 & -0.000004 \\
3 & 5.999994 & -2.000004 & 0 \\
4 & 3.999991 & -2.000004 & 0.000035 \\
5 & 2.000005 & -1.999968 & 0.999955 \\
6 & 0.500015 & -1.000013 & 1.000004 \\
7 & 0.000004 & -0.000009 & \\
\hline
\end{tabular}

Table 2 Exact optimum solution of the minimumtime solution of the example

\begin{tabular}{c|c|r|r}
\hline$\underset{k}{\operatorname{time}}$ & $x^{1}(k)$ & $x^{2}(k)$ & $u(k)$ \\
\hline 0 & 10 & 0 & -1 \\
1 & 9.5 & -1 & -1 \\
2 & 8 & -2 & 0 \\
3 & 6 & -2 & 0 \\
4 & 4 & -2 & 0 \\
5 & 2 & -2 & 1 \\
6 & 0.5 & -1 & 1 \\
7 & 0 & 0 & \\
\hline
\end{tabular}

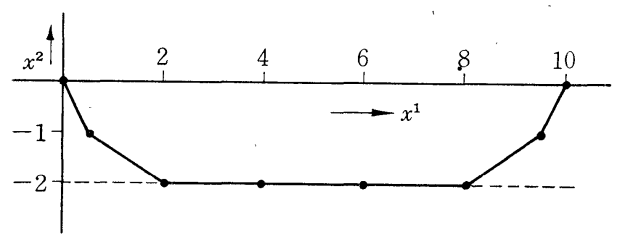

Fig. 2 Phase trajectory of state of Table 1

\section{5. 議論および結論}

(13)〜 (15) 式からあきらかなように理論的には $\varepsilon_{i}$ が小さい汪ど解の精度はよいが, 実際には計算機の計

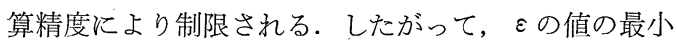
限度があらかじあわかってい机ば，をを数列的に変化 させる必要はなく, $\varepsilon$ が最小限度の值のとき得られる 解が, もっともよい近似解といらことになるが, 実際 飞は, 前述のように, そのようなををあらかじめ知る
ことは困難である。したがって， ある程度大きな $\varepsilon_{1}$ から計算をはじめて, 徐々に小さくしていく方法が適 当と思われる. また計算機的には倍精度計算が望まし いといらことになるが，例題の解は単精度計算でも満 足すべき解が得られる可能性を示している.

以上のように; 状態牤よび操作量に制限がある場合 の非線形離散值系の最短時間問題の数值解が，罰関数 法を用いることにより，かなり簡単なアルゴリズムで 得られることがわかる。またそのアルゴリズムに関連 して, ヘビサイドのステップ関数を含む関数の極值探 索に有用と思われるアルゴリズムを示し，例題の計算 結果から，この方法がかなり有用であることがわかっ た。

\section{参 考 文 献}

1) E. B. Lee : Recurrence Equations and the Control of Their Evolution, J. Math. Anal. and Appl., Vol. 7, 118/126 (1963)

2) R. W. Koepcke : A Solution to the Sampled, Minimum-time Problem, 1963 JACC, 94/100 (1963)

3) J. H. Eaton : An On Line Solution to Sampleddata Time Optimal Control, J.Electron. Control, 15-4, 333/341 (1963)

4) J. Pokoski : An Analysis Scheme for Suboptimal Minimum-time, Sampled-data Systems, 1968 JA CC, 270/287 (1968)

5）伊藤：線形離散值系の 2 次評価を用いた最短時間問題 の準最適解, 計測自動制御学会論文集, 7-4, 303/309 (1971)

6) R. Fletcher \& M. J. D. Powell : Rapidly Convergent Desent Method for Minimization, Computer Journal, 6-2, 163/168 (1964)

7) R. Fletcher \& C. M. Reeves : Function Minimization by Conjugate Gradients, Computer Journal, 7-2, 149/154 (1964)

8) W. I. Zangwill : Non-linear Programming via Penalty Functions, Management Science, 13-5, 344/ 358 (1967)

9) A.V.Fiacco \& G.P. McCormick: The Sequential Unconstrained Minimization Technique for Nonlinear Programming, A Primal-Dual Method, Management Science, 10-2, 360/366 (1964)

10）伊藤 : 状態制限付非線形離散値系の最短時間問題の解 法，第14 回自動制御連合講演会, 1105 (1971)

11) J. T. Tou : Optimum Design of Digital Control Systems, Academic Press (1963) 